\title{
Ah
}

\section{El turismo como estrategia del Estado: visiones políticas y aportes técnicos en Mendoza (1936-1943)}

\author{
[Tourism as a Strategy of the State: Political Visions and Technical Contributions \\ in Mendoza (1936-1943)]
}

\author{
Cecilia Raffa \\ (Instituto de Ciencias Humanas, Sociales y Ambientales / Consejo \\ Nacional de Investigaciones Científicas y Técnicas) \\ craffa@mendoza-conicet.gob.ar
}

\begin{abstract}
Resumen:
Este artículo avanza sobre las políticas referidas a la promoción turística de Mendoza en los años treinta y sus materializaciones, a través de la acción de las Direcciones de Turismo y Arquitectura de la provincia. Entendemos que el análisis de las vinculaciones entre las visiones políticas que buscaban posicionar a la provincia como destino y los aportes técnicos para la construcción de equipamiento para el turismo, permite colocar las acciones del gobierno liberalconservador en Mendoza como uno de los primeros ejemplos a nivel nacional que marcaron el paso entre las experiencias del turismo/ocio de élite de principios del siglo XX y la democratización social de esta práctica durante el primer Peronismo.
\end{abstract}

Palabras claves: Arquitectura de Estado; Turismo; Políticas Públicas

\begin{abstract}
:
This article advances on the first policies referred to the tourist promotion of Mendoza in the thirties and its materializations, through the action of the Tourism and Architecture Directorates of the province. We understand that the analysis of the links between the political visions that sought to position the province as a destination and the technical contributions for the construction of tourism equipment, allows placing the actions of the conservative government in Mendoza, as one of the first examples at a national level that marked the transition between the experiences of elite tourism / leisure at the beginning of the 20th century, and the social democratization of this practice during the Peronism.
\end{abstract}

Keywords: State architecture; Tourism; Public Policies

Recibido: 29/05/2019

Evaluación: 01/08/2019

Aceptado: 01/09/2019

Anuario de la Escuela de Historia Virtual - Año 11 - N 17 - 2020: pp. 104-127.

ISSN: 1853-7049

http://revistas.unc.edu.ar/index.php/anuariohistoria 


\section{El turismo como estrategia del Estado: visiones políticas y aportes técnicos en Mendoza (1936-1943)}

A partir de la primera posguerra y en sintonía con lo que pasaba en otros lugares del mundo, en Argentina se fue ampliando la disponibilidad de tiempo de ocio para distintos grupos sociales que empezaron a percibir a las vacaciones como una actividad a su alcance. Sectores medios comenzaron a recorrer los enclaves donde originalmente vacacionaban los miembros de la elite (Ospital, 2005). A los destinos ya consagrados, como Mar del Plata o las sierras cordobesas (Pastoriza, 2011), se sumaron a partir del auge del automóvil y la expansión de la red de caminos y de estaciones de servicio en los años treinta, otros sitios que interesaron a los nuevos paseantes, como el noroeste argentino, la región de los lagos patagónicos y los Andes centrales. ${ }^{1}$ También se extendieron nuevas formas de practicar el turismo como el camping, el recorrido de rutas o las visitas a hitos históricos (Ballent, 2005; Piglia, 2008a).

El turismo fue construyéndose socialmente como un asunto de bien público, resaltando sus beneficios pedagógicos, patrióticos e higiénicos para el conjunto social (Piglia, 2008b). Los cambios culturales y sociales que, desde los años veinte, habían convertido a las prácticas turísticas en actividades algo más habituales para estratos medios de la población, y las campañas instrumentadas desde ámbitos deportivos, asociaciones civiles, compañías ferroviarias y empresarios del automotor, contribuyeron a instalar las nuevas costumbres (Ospital, 2005). La ley de sábado inglés, la de vacaciones pagas, las rebajas tarifarias de los trenes turísticos, fueron iniciativas, algunas provenientes de la década anterior, que colaboraron con el fomento del turismo (Ballent, 2005).

Según Piglia (2011), la difusión de estas concepciones colaboraron para que paulatinamente el turismo fuera asumido como una actividad social que el Estado podía regular, promoviendo los destinos tradicionales y organizando nuevos a través de la construcción de hoteles, caminos y atractivos. La promoción del "despertar del turismo" para descubrir el paisaje argentino, se mezcló con la idea cada vez más firme, hacia el

\footnotetext{
${ }^{1}$ El Automóvil Club Argentino (ACA) y el Touring Club Argentino, fundados en los primeros años del siglo $\mathrm{XX}$, se ocuparon de destacar las ventajas aportadas por el uso de automóviles para el turismo. Estas asociaciones se encargaron de difundir consejos para superar los problemas mecánicos planteados por la tecnología recién llegada y de publicar planos camineros del país a fin de incentivar los recorridos fuera de las áreas urbanas. Colaboraron, además, con el Estado en el impulso de políticas que vincularon el desarrollo de la infraestructura caminera y el turismo (Ospital, 2005; Ballent, 2005; Piglia, 2014; Pastoriza y Piglia, 2012). En Mendoza, desde 1920, aparecen en los periódicos locales noticias sobre la acción de asociaciones civiles vinculadas al automóvil (Automóvil Club Mendoza, Motor Club Mendoza, etc.) organizando excursiones a zonas de montaña, competencias automovilísticas en el Parque General San Martín, entre otras. De hecho, Mendoza es sede en 1930 de la Segunda Conferencia Nacional y Semana del Turismo por ser una de las provincias que comenzaba a impulsar esa práctica. Los Andes, 18 de agosto de 1925, p. 6; Los Andes, 13 de febrero de 1930, p. 11.
}

Anuario de la Escuela de Historia Virtual - Año 11 - Nº 17 - 2020: pp. 104-127. ISSN: 1853-7049 
interior del Estado, del turismo como una nueva industria. Se esperaba que la actividad generara ingresos económicos que ayudaran a paliar los efectos de la crisis económica internacional de 1929, llevando progreso y civilización a las regiones atrasadas, incentivando el empleo a través de la obra pública y fortaleciendo la unidad nacional.

Durante las gestiones conservadoras, el gobierno nacional le otorgó mayor relevancia al Ministerio de Obras Públicas de la Nación, bajo cuya órbita se encontraba la Dirección Nacional de Vialidad, creada en 1932. Esa novel repartición desarrolló una intensa labor, partiendo de $2.000 \mathrm{~km}$ de vías asfaltadas en 1932, para llegar a $30.000 \mathrm{~km}$ en 1944 (Ballent, 2005). El proyecto original, que se centraba en el tendido de carreteras para servir a la producción agrícola-ganadera, postergando la construcción de las grandes vías aptas para el turismo, fue modificado parcialmente en beneficio de la segunda opción, dada la creciente importancia que esta actividad adquirió en ámbitos civiles y estatales. ${ }^{2}$

También se creó en el ámbito del Ministerio de Agricultura, mediante la ley $\mathrm{N}^{\circ}$ 12103/34, la Dirección General de Parques Nacionales, jalonando decididamente el rol del Estado como administrador del desarrollo turístico de la Nación. Esta Dirección fue, tal como lo sostiene Piglia, el primer ensayo nacional de una política sistemática basada en un modelo de planificación, fomento y regulación centralizados por el Estado de la actividad turística. ${ }^{3}$

En este marco, este artículo avanza sobre las primeras reglamentaciones referidas a la promoción turística de Mendoza entre 1936 y 1943 y sus materializaciones, a través de la acción de las Direcciones de Turismo y Arquitectura de la provincia. Nos centramos en la caracterización de las vinculaciones entre las visiones políticas que buscaron posicionar a la provincia como destino y los aportes técnicos para la construcción de equipamiento para el turismo. Entendemos que esas acciones del gobierno liberalconservador en Mendoza ${ }^{4}$ impulsaron uno de los primeros ejemplos a nivel nacional de concreción de políticas públicas vinculadas al Turismo como nueva injerencia del Estado.

\footnotetext{
2 Por ejemplo, la expansión de la red caminera incluyó el trazado de la ruta 2, uniendo a partir de 1938 a la ciudad de Buenos Aires con Mar del Plata, el balneario argentino más importante, con un camino pavimentado (Ospital, 2005).

${ }^{3}$ El fomento y la organización del turismo en los Parques Nacionales, que incluían el Iguazú y el Nahuel Huapi, ocuparon un lugar central en la política turística nacional. Se puso principal atención en el parque patagónico que era, de acuerdo a la visión del momento, el que tenía mayores potenciales y cuya explotación suponía el cuidado de una frontera poco atendida por el Estado. Sobre la Dirección de Parques Nacionales puede verse en Piglia (2012).

${ }^{4}$ Hacemos referencia a la etapa que, a nivel nacional, se abre con la llegada a la presidencia de la Nación de Agustín P. Justo en 1932 y que, en la provincia de Mendoza, marca el periodo 1932-1943, bajo las gobernaciones de Ricardo Videla (1932-1935), Guillermo Cano (1935-1938), Rodolfo Corominas Segura (1938-1941) y Adolfo Vicchi (1941-1943). Reciben estos dirigentes provinciales la caracterización de liberalconservadores, en referencia a la adopción que hicieron del conservadorismo de antaño "aggiornado" como forma política de gobernar, tomando el liberalismo como ideología (Pérez Ghilou, 1997).
}

Anuario de la Escuela de Historia Virtual - Año 11 - Nº 17 - 2020: pp. 104-127. ISSN: 1853-7049 
Complementarios a las acciones y discursos desplegados en el ámbito nacional por miembros de los distintos poderes nacionales, ${ }^{5}$ en Mendoza se comenzaron a idear instrumentos que posibilitaron tanto la promoción turística de la provincia como su regulación. Impulsadas a través del Ministerio de Industrias y Obras Públicas, ${ }^{6}$ primero a cargo de Frank Romero Day y luego de José María Alurralde, se aprobaron las leyes $\mathrm{N}^{\circ} 1216 / 37$ y $\mathrm{N}^{\circ} 1298 / 38$ y sus complementarias $\mathrm{N}^{\circ} 1351 / 39$ y $\mathrm{N}^{\circ} 1401 / 41$. La primera de ellas, basada en una propuesta inicial presentada por el senador oficialista Alfredo Godoy, creó la Dirección Provincial de Turismo y contempló diversos estímulos a la inversión privada. La segunda habilitó la posibilidad de que el Estado provincial construyera distintos alojamientos y los concesionara. En los enclaves elegidos, se privilegiaron los paisajes con contrastes soberbios, picos nevados, torrentes de ríos y arroyos y fuentes termales: la montaña seguía siendo la gran atracción turística de la provincia. Asimismo, se realizó una fuerte inversión en el mejoramiento de sitios y lugares históricos y se planificaron recorridos turísticos vinculando los departamentos del interior de la provincia. También se institucionalizó la Fiesta de la Vendimia. El impulso político estuvo enfocado tanto en obtener rédito económico a partir del arribo de turistas nacionales y extranjeros, como en extender las posibilidades del ocio a los sectores medios locales. ${ }^{7}$

El escrito que presentamos se vincula a una serie de estudios sobre la historia del turismo en Argentina; indagaciones que se suman a la nutrida literatura que se ha producido en el ámbito internacional y que analiza, entre otros aspectos, la vinculación entre las representaciones, las prácticas recreativas y las políticas públicas afines a esa actividad. ${ }^{8}$

\footnotetext{
${ }^{5}$ Piglia (2011a) se refiere, por ejemplo, al debate parlamentario de la Ley Nacional de Vialidad y a las expresiones en la prensa del Ministro de Obras Públicas de la Nación, Manuel Alvarado, entre otros. En esos discursos, se defendía la importancia económica y social de la construcción de los caminos de turismo y se enfatizaba la dimensión patriótica del turismo.

${ }^{6}$ En 1938, mediante la ley 1294, esta agencia pasó a denominarse Ministerio de Economía, Obras Públicas y Riego (Recopilación de Leyes, 1942).

${ }^{7}$ En la consecución de esos objetivos fueron fundamentales también los aportes de las Direcciones de Parques, Calles y Paseos de Mendoza y Provincial de Vialidad. La primera, dirigida a partir de 1938 por el arquitecto Daniel Ramos Correas, se ocupó del mejoramiento de los espacios públicos más importantes de la provincia, entre ellos el Parque General San Martín (Raffa, 2011). Por su parte, el desarrollo histórico de las villas de montaña y de la arquitectura destinada al turismo, estuvo marcadamente influenciado por los medios de transporte. El tren primero y el automóvil luego, a través de la acción que las Direcciones Nacional y Provincial (1933) de Vialidad llevaron adelante, fueron impulsando la habilitación de nuevos trayectos para la RN 7 y RN 40. Entre 1935 y 1941 se construyeron 1.149 puentes en la provincia. Hacia 1941, la extensión de la red provincial de caminos alcanzó los $4.092 \mathrm{~km}$, mientras que la nacional que pasaba por Mendoza se había extendido hasta llegar a un total de $954.322 \mathrm{~km}$ (Corominas Segura, 1942). Estos caminos servían tanto para ofrecer a los turistas mejores condiciones para sus traslados, como para el transporte de los productos agrícolas e industriales producidos en Mendoza.

${ }^{8}$ En el ámbito internacional podemos citar a los clásicos trabajos sobre el turismo de Corbin (1993) y Walton (1983). En Argentina, se han desarrollado indagaciones que ponen el foco en el estudio de la historia de las localidades turísticas y balnearios: Pastoriza (2003 y 2011), Torre y Patoriza (2002); en el equipamiento hotelero, Bruno (2010); y en el papel de las asociaciones civiles y la transformación del turismo en política pública en las primeras décadas del siglo XX: Piglia (2008a, 2008b, 2011a, 2011b, 2012 y 2014), Ballent (2005), Ballent y Gorelik (2002), Ospital (2005), Pastoriza y Piglia (2012). Aunque son las políticas de turismo social
} 
El artículo se inicia recorriendo las características de las prácticas y el equipamiento vinculados al ocio en Mendoza a principios del siglo XX, para luego analizar el alcance de la serie de leyes reglamentadas en los años '30, que impulsaron la creación de la Dirección de Turismo, la promoción de la provincia como destino y la inversión en equipamiento para el ocio y la recreación, ejecutados por la Dirección de Arquitectura. ${ }^{9}$ Las conclusiones indican los primeros resultados alentadores logrados mediante el impulso al turismo para los sectores medios como estrategia económica y cultural por parte del Estado provincial. Caracterizamos el abordaje de políticas y arquitecturas públicas ejecutadas para fortalecer la industria del turismo a través del análisis cualitativo de fuentes documentales (leyes y memorias de gobierno, principalmente) y gráficas (prensa, proyectos arquitectónicos).

\section{Visite Mendoza, la tierra del sol y del buen vino}

Mendoza fue siempre un lugar de paso para quienes circulaban entre el Atlántico y el Pacífico; en algunas de esas travesías, los viajeros aprovechaban las propiedades termales de Puente del Inca o Cacheuta, sitios nombrados en sus crónicas, por lo menos, desde el siglo XVII. A partir de las últimas décadas del siglo XIX, en correlación con el proceso de organización nacional y la consolidación del modelo económico agroexportador, esas fuentes termales se constituyeron en un destino para el descanso y la sanación a raíz de sus propiedades curativas. La hidroterapia comenzó a desarrollarse junto a un importante conjunto de técnicas que utilizaban el agua como único fármaco: vapores, algas, barros y arcillas en su estado más natural.

El siglo XX propició el comienzo de un turismo de sectores sociales acomodados quienes, emulando prácticas de grupos europeos con los que se identificaban, comenzaron a viajar con fines turísticos hacia algunos lugares del país, entre ellos, Mendoza. Aparecieron entonces, los centros termales inmersos en paisajes naturales

impulsadas por el primer peronismo las que más interés han concitado a nivel nacional: Pastoriza (2002 y 2008), Piglia y Pastoriza (2017) y Raffa (2018c), entre otros.

En lo que respecta a Mendoza, los estudios vinculados al turismo aún son incipientes y parciales; puede destacarse la información prevista por Lacoste y otros (1996) y el trabajo de Cremaschi (2015), sobre aspectos estéticos vinculados a los hoteles construidos en los años treinta.

${ }^{9}$ En la Dirección de Arquitectura se proyectaron todas las obras de arquitectura pública derivadas de las políticas provinciales del período, incluyendo las de alojamiento, ocio y esparcimiento en zonas urbanas, suburbanas y de montaña. También estuvo a su cargo, a partir de 1937 y durante varias décadas, el diseño de los escenarios de las sucesivas celebraciones de la Fiesta de la Vendimia. Los lineamientos de los proyectos encarados, fueron puestos en marcha gracias a una característica particular de los años de gobierno conservador: la permeabilidad que las propuestas ideadas por el campo técnico tuvieron en el campo político. Como hemos demostrado en trabajos anteriores, esto se dio sobre la base de la estrecha relación que agentes de uno y otro campo tuvieron por su capital simbólico común. Esta particularidad posibilitó que proyectos arquitectónicos que empezaban en una gestión fuesen terminados en las sucesivas, respetando criterios de lenguaje y tipología y definiendo los rasgos de homogeneidad en la planificación y ejecución de obra pública que caracterizó a todo el ciclo (Raffa, 2016).

Anuario de la Escuela de Historia Virtual - Año 11 - No 17 - 2020: pp. 104-127. ISSN: 1853-7049 
rodeados de cerros nevados, con hoteles organizados en torno a las salas de baño y las funciones curativas.

Tras la llegada del Ferrocarril Trasandino a la localidad cordillerana de Puente del Inca en 1902, se edificó el Hotel Termas de Puente del Inca, con capacidad para cien personas. Construido por la Compañía de Hoteles Sudamericana, entidad subsidiaria del FC Pacífico, este hotel marcaría un hito en la historia del turismo de montaña y en la práctica de los deportes invernales como patinaje, hockey sobre hielo y sky, principalmente a partir de 1930 (Lacoste et al., 1996).

Tal como Puente del Inca, la zona de Cacheuta gozaba de reconocimiento por sus aguas termales. En 1913, se inauguró el Hotel Termas de Cacheuta, luego de un concurso impulsado por el Estado para la explotación del lugar, cuyo resultado fue la concesión a una empresa privada, que más tarde se convertiría en la Sociedad Anónima Termas de Cacheuta. El hotel se transformó rápidamente en un polo de referencia para el turismo nacional e internacional. Cacheuta recibió en 1916 más de 30.000 pasajeros, cifra que volvió a repetirse en 1919 (Lacoste et al., 1996).

El aluvión de 1934 en el Cajón del río Mendoza ${ }^{10}$ hizo que el funcionamiento de estos emprendimientos fuera desde ese momento intermitente, si bien el fenómeno no afectó directamente las instalaciones hoteleras, sí lo hizo con el trazado del Trasandino, principal medio de locomoción hacia la zona de montaña y los hoteles. El aluvión paralizó el transporte por Cacheuta y Potrerillos e indirectamente provocó la reactivación de la RN7 a través de Villavicencio.

Mientras se trabajaba en la reactivación de los emprendimientos de Puente del Inca y Cacheuta, en 1935, surgió en la zona de montaña otro hotel en Uspallata. Este hotel fue el resultado de la transformación que la Compañía de Hoteles Sudamericanos hizo del edificio principal de la antigua estancia Uspallata. El hotel tenía la ventaja de estar ubicado sobre el camino internacional a Chile, por lo cual, podía prescindir del ferrocarril, ya que los turistas llegaban a él en automóvil.

Con un turismo de montaña fuertemente desarrollado por inversiones privadas y mixtas, ${ }^{11}$ durante el ciclo conservador, esa actividad comenzó a tener la importancia de una industria fecunda y provechosa para la provincia. Durante la gestión de Ricardo Videla (1932-1935), apareció en el organigrama del Ministerio de Industrias y Obras Públicas la Sub-secretaría de Industria, Propaganda y Turismo, cuyas incumbencias estuvieron orientadas promocionar Mendoza como destino, complementando las acciones de distintos actores como las empresas de transporte y los hoteles. ${ }^{12} \mathrm{Al}$ final del mandato de Videla, en febrero de 1935, en la revista C.I.T.A. editada por la Compañía

\footnotetext{
${ }^{10}$ Este aluvión supuso la pérdida de 150 kilómetros de vías, lo que dejó fuera de servicio al Trasandino por más de una década y reactivó la antigua RN 7 que pasaba por la localidad lasherina de Villavicencio (Pastor y Raffa, 2013).

${ }^{11}$ En el caso de Cacheuta, por ejemplo, el Estado también realizó inversiones (Lacoste et al., 1996).

${ }^{12}$ Los subsecretarios de la repartición detectados fueron Tomás Burgos Terán y Ramón Corti Videla, quien sería luego el primer director de Turismo (C.I.T.A, El turismo en Mendoza, Nº 1, octubre 1934, s/p).
} 
Internacional de Transportes Automóviles S.A., se hace mención al Departamento Provincial de Turismo, un antecedente directo de la Dirección que se concretaría poco tiempo después. ${ }^{13}$

A partir de la gestión de Guillermo Cano (1935-1938), comenzó a gestarse un programa más amplio que incluía, además de la promoción, la inversión de recursos en equipamiento. Los objetivos principales para potenciar a Mendoza como destino eran la atracción de visitantes y el conocimiento y goce de los propios habitantes de la provincia de las bellezas y riquezas de su suelo. Se darían a conocer en forma sistemática y permanente dentro y fuera del país: el clima sano y agradable con hermoso sol en invierno y noches frescas en verano, seco y libre de parásitos y fiebres endémicas; los paisajes variados y magníficos de contrastes soberbios con montañas, ríos y arroyos; las fuentes termales numerosas y abundantes con propiedades curativas y capaces de aliviar las peores situaciones crónicas (reumatismo, problemas en la piel, enfermedades digestivas, etc.); los productos regionales, buenos y variados -vino, chicha, licores, uvas y otras frutas frescas, dulces y mermeladas, pasteles, tabletas y platos de la cocina local(Recopilación de Leyes, 1938, pp. 367 y ss.); y los sitios donde ocurrieron hechos dignos de rememorar como la epopeya sanmartiniana. Algunos de esos sitios fueron incorporados, a partir de 1941, en el listado de bienes protegidos por la entonces Comisión Nacional de Museos, Monumentos y Lugares Históricos, remarcando su valor. $^{14}$

Los usos y costumbres, las fiestas y las celebraciones también se sumaron a esas atracciones. Es el caso de la Fiesta de la Vendimia, que, desde 1936, se institucionalizó como "la fiesta del trabajo de los mendocinos". En efecto, el Gobierno introdujo el festejo anual en la época de la cosecha, de la fiesta de la uva y el vino como se hacía en algunas ciudades europeas (Palermo, Bordeaux), pero "inventando una tradición" con sello propio. En marzo de 1936, el decreto 87, instituyó con carácter permanente esa celebración que conforme pasó el tiempo se fue perfeccionando y complejizando.

El cultivo de la vid y su industrialización constituyeron a partir de ese momento la representación más acabada del trabajo mendocino que mediante esa celebración exaltaba el orgullo sobre una producción que promovía la riqueza colectiva. El espacio público mendocino fue el contenedor de esos festejos que se iniciaron en 1936 con el Carrusel: un desfile de carros alegóricos en el Parque General San Martín y que, en la medida que crecía la escala de espectadores locales y foráneos, fue desplegándose por

${ }^{13}$ Esta compañía se dedicó al transporte de pasajeros en la provincia, vinculando distintos parajes de Mendoza entre sí y, además, la provincia con otros destinos nacionales. En la revista editada con tiraje mensual, se hacía promoción a distintos enclaves mendocinos (C.I.T.A., Sobre el turismo en Mendoza, $\mathrm{N}^{\circ} 8$, mayo 1935, s/p).

${ }^{14}$ La Comisión tiene su origen en el año 1938. Se creó con el fin de unificar la administración y el control del patrimonio histórico-cultural de la Nación. Un amplio porcentaje de los bienes declarados patrimonio nacional hasta la década del 1970 tuvieron directa relación con la historia político-militar y religiosa de Argentina. Información recuperada

de: https:/www.cultura.gob.ar/institucional/organismos/museos/comision-nacional-de-museos-y-demonumentos-y-lugares-historicos/ (Consultado el 20 de mayo de 2019). 
las calles de la ciudad capital y sumando nuevos actos. La Bendición de los frutos, por ejemplo, se realizó por primera vez en 1938 y la primera Vía Blanca de las reinas sucedió en 1940. Esta Fiesta, en la que se elige año a año "una reina de los viñateros" entre las representantes de todos los Departamentos de la provincia, se constituyó en uno de los más importantes atractivos de la provincia que, a modo de un ritual fue (y es) la piedra de toque de la promoción turística de Mendoza desde los años treinta. ${ }^{15}$

Bellezas naturales, riquezas termales, cultura y fiesta serían las "sólidas bases" sobre las que podía construirse la "gran industria del turismo" y que rara vez, según el Ejecutivo provincial, se encontraban reunidos en un solo lugar. De todos modos, la empresa suponía una acción público-privada y una fuerte inversión de recursos económicos.

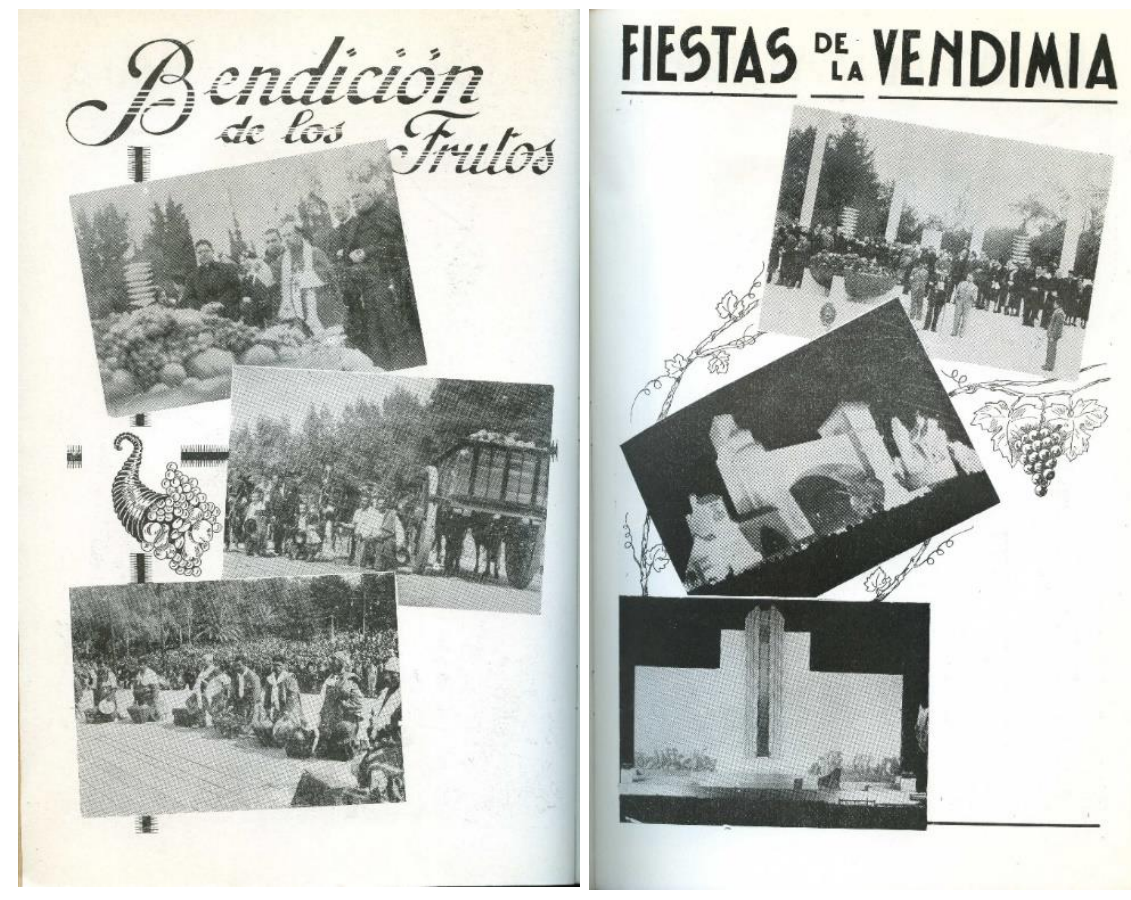

Fuente: Ministerio 1941

\footnotetext{
${ }^{15}$ Si bien se han establecido en Mendoza celebraciones previas vinculadas a la vendimia, fue en 1936 cuando este homenaje al trabajo de los viñateros se convierte en tradición. Un análisis detallado de los orígenes de la Fiesta y sus particularidades puede verse en: Marchionni, 2012.
} 


\section{La ley $\mathrm{N}^{\circ} 1216 / 37$ y el respaldo a la iniciativa privada}

Con fecha 17 de mayo de 1936, el diario Los Andes publicó la Ley Orgánica de Turismo de la provincia de Mendoza, dando a conocer a los lectores el proyecto que había enviado el Ejecutivo para su tratamiento en la Legislatura dos días antes. Este proyecto proponía la creación de la Dirección de Turismo de Mendoza (DTM), la primera oficina estatal de escala provincial creada en el país para ocuparse de esta nueva política de Estado, ${ }^{16}$ y el financiamiento de las actividades que la repartición llevase adelante. Este instrumento creaba también la Casa de Mendoza, una sub-sede de la Dirección Provincial de Turismo, encargada de promover los atractivos de la provincia en la Capital Federal.

Como parte del Ministerio de Industrias y Obras Públicas, la DTM sería la encargada de organizar la explotación turística de la provincia, consiguiendo facilidades para los viajes, organizando excursiones, publicitando la provincia por medios oficiales y privados y velando por la seguridad, el confort, la higiene y la estética de los edificios para hospedaje de turistas y sus instalaciones. Para ello, podía habilitar lugares para la práctica del camping y los deportes; construir caminos, sendas y pequeñas obras de arte para el acceso a los hoteles, hosterías y sitios de turismo; organizar fiestas regionales como la de la Vendimia, conservar y fomentar la arboleda y toda otra especie vegetal que destacase el paisaje mendocino; impulsar la visita a Mendoza de compañías de espectáculos, conciertos, etc. y estimular la instalación de pequeños comercios para la venta de productos regionales, entre otras acciones. La repartición estaría facultada, además, para invertir hasta $\$ 100.000$ en la restauración de lugares históricos, la creación de paseos y la construcción de miradores y quioscos en lugares de turismo (Recopilación de Leyes, 1938, pp. 363 y ss.). A través de la sección de Estadística e Información, editaría guías oficiales, planos, información sobre hotelería, clima, precios, etc.

Esta nueva dependencia sería dirigida por un especialista y contaría con un Consejo Consultivo ad honorem con el fin de coordinar las acciones de gobierno con las de otros organismos, asociaciones civiles o dependencias municipales en lo referido a la promoción turística de Mendoza. Serían parte de ese Consejo representantes de las Municipalidades de la primera, segunda y tercera jurisdicción electoral, de ferrocarriles con líneas a la provincia, de la Dirección Provincial de Vialidad, el Automóvil Club Argentino, el Touring Club Argentino y el Automóvil Club Mendoza. ${ }^{17}$ También formarían parte del Consejo, empresas de transporte automotor para pasajeros, el

\footnotetext{
${ }^{16}$ En provincia de Buenos Aires, por ejemplo, la política turística tuvo impulso sobre todo en la gobernación de Manuel Fresco (1936-1940), y se desprendía de las políticas del Ministerio de Obras Públicas, encabezado por José María Bustillo. Recién en 1939 se creó en el ámbito provincial una comisión honoraria de parques provinciales y turismo, para asesorar en esos temas y en la órbita del Ministerio de Obras Públicas. La existencia de una repartición estatal específica es de la primera gobernación peronista encabezada por Domingo Mercante. A nivel nacional la creación de la Dirección Nacional de Turismo tuvo varios intentos de formación durante la gestión conservadora y terminó funcionando entre 1942 y 1943 (Piglia, 2011a).

${ }_{17}$ A partir de la instauración de la Fiesta de la Vendimia, el ACA filial Mendoza comenzó a organizar el Gran Premio Vendimia, un circuito que se incluyó en los programas de la Asociación a nivel nacional. Los Andes, 30 de enero de 1940, p. 10.
} 
gremio de hoteleros, empresas y agencias de turismo radicadas en la provincia, el Círculo de Periodistas, la Federación de Deportes y la Unión Comercial e Industrial de Mendoza (Recopilación de Leyes, 1938, pp. 363 y ss.).

El primer director de la repartición fue Ramón Corti Videla a quien le sucedieron Francisco Correa, durante la gobernación de Corominas Segura (1938-1941) y Adolfo Mosquera Suárez en la gestión de Adolfo Vicchi (1941-1943). ${ }^{18}$ El organigrama de la repartición se completaba con un jefe de propaganda, oficial, auxiliar y el encargado de la delegación en Buenos Aires, quien también tenía bajo su mando un reducido grupo de auxiliares. ${ }^{19}$

Con carácter extraordinario, la ley facultaba al Ejecutivo a invertir para los años 1936, 1937 y 1938, hasta la cantidad de $\$ 350.000$ en gastos de propaganda y fomento al turismo. Se preveía que los gastos que demandara el cumplimiento de la ley se atenderían con títulos denominados "Títulos de Turismo de la provincia de Mendoza", hasta la suma de $\$ 1.300 .000 .{ }^{20}$

A partir de 1937, se prepararon y difundieron en el país y el exterior, guías y folletos con información necesaria para el turista. Se buscaba atraer a los sectores medios (profesionales liberales, comerciantes, docentes, pequeños industriales, etc.), la masa social más densa y con posibilidades monetarias para hacer turismo y colaborar en el consumo de los productos regionales. ${ }^{21}$ Se difundieron listas de hoteles con direcciones y precios; guías destinadas a lugares históricos, eventos culturales y religiosos como el Campo Histórico el Plumerillo, el Parque Gral. San Martín, la Fiesta de la Vendimia, el Camping de Potrerillos, Antiguas Artes de Mendoza, la ruta del Ejército de los Andes y la Virgen de la Carrodilla. Más adelante en la gestión, comenzaron a promocionarse circuitos que relacionaban departamentos de la provincia, como el Circuito Luján-Maipú (1941), el de Junín-Rivadavia y la vinculación de Mendoza con la Patagonia, a través de la propuesta "ruta por Mendoza a los Lagos del Sud" (1942). Esta iniciativa tenía el objetivo de sumar a Mendoza como alternativa para llegar desde el Litoral o la Capital Federal a los parques patagónicos que contaban con una gran promoción turística por parte de la Nación.

La DTM también editó folletos sobre las industrias locales sumándose a la promoción que suponía la realización anual de la Feria/Exposición Industrial, organizada por el

\footnotetext{
18 Sin especialistas en turismo, el cargo de director durante el período estudiado estuvo mayormente ocupado por abogados. AHM, Dirección Provincial de Turismo, Expediente 57; Los Andes, 17 de febrero de 1941, p. 7; Vicchi, 1943.

${ }^{19}$ Guía General de Mendoza, edición 1940, pp. 190-191.

${ }^{20}$ En su art. 30, la ley especifica que los títulos a emitir serían del 5\% de interés anual, pagaderos por trimestres vencidos, y de 1\% de amortización anual acumulativa pagadera a semestres vencidos por compra en mercado abierto o licitación. (Recopilación de Leyes, 1938, pp. 363 y ss.).

${ }^{21}$ El salario real mensual en la ciudad de Buenos Aires en 1939 ascendía a \$ 97 de acuerdo a los datos proporcionados por la Dirección Nacional de Trabajo (Vázquez-Presedo, 1976, p. 46). En tanto, el alojamiento por noche en habitación individual con baño en la ciudad de Mendoza oscilaba entre los \$3 y los \$14, dependiendo del hotel elegido (EMETUR, Dirección de Turismo, Folleto Bienvenido a la tierra del sol y del buen vino, 1939).
}

Anuario de la Escuela de Historia Virtual - Año 11 - Nº 17 - 2020: pp. 104-127. ISSN: 1853-7049 
Ministerio de Economía, Obras Públicas y Riego, en paralelo a las celebraciones de la Vendimia. $^{22}$

Figuras 2. Serie de folletos y guías para promocionar Mendoza
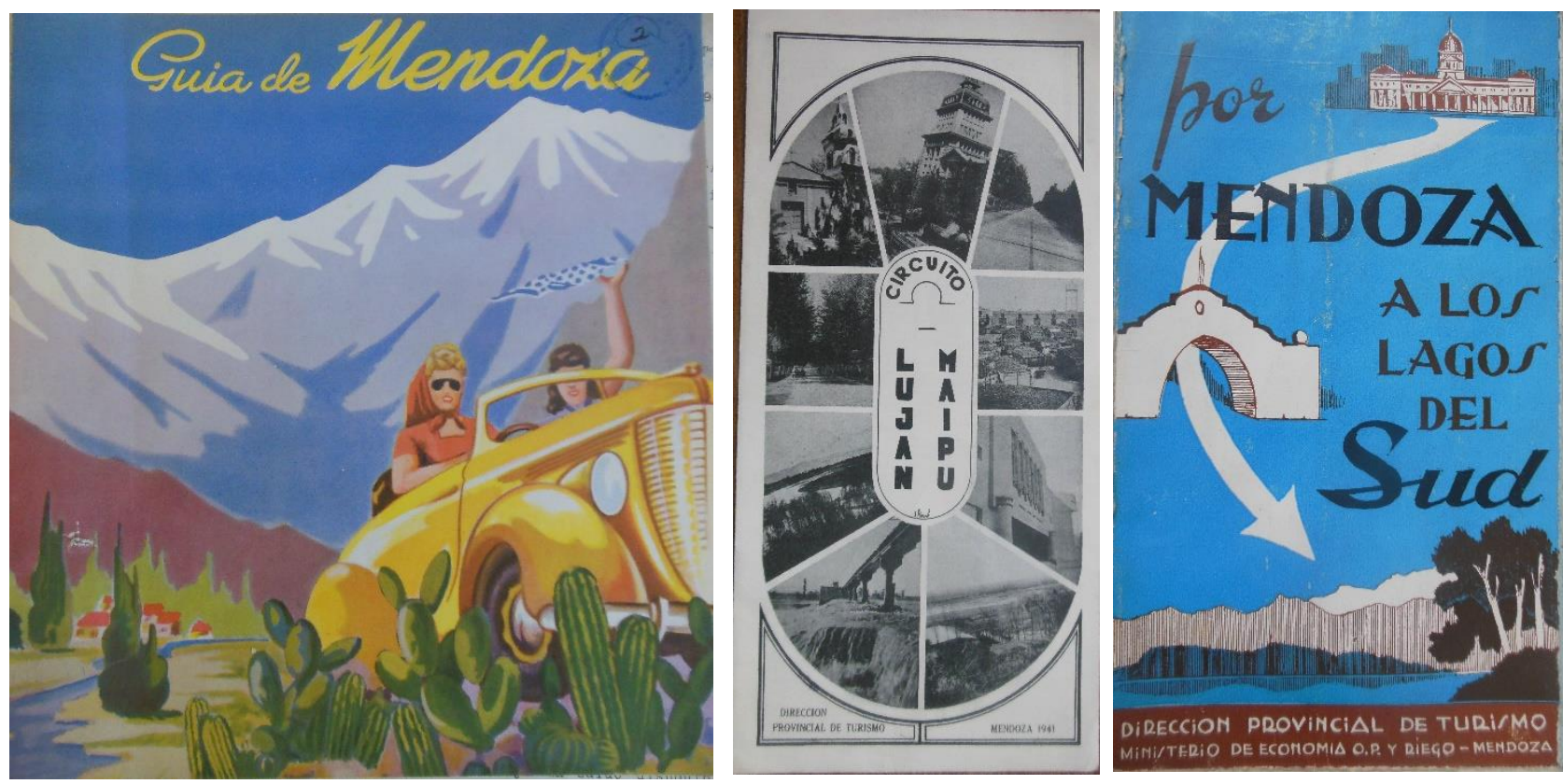

Fuente: AHM, Dirección Provincial de Turismo, Expediente 57/ EMETUR, Dirección de Turismo de Mendoza. Folletos y guías informativos, 1937-1942.

Sin embargo, no solo había que atraer al turista con las características "inigualables" de Mendoza, también había que alojarlo y distraerlo y, en ese sentido, los alojamientos en la capital provincial eran insuficientes, tanto como en el resto de la provincia donde, en general, estaba todo por hacerse. ${ }^{23}$ Embarcado el Estado provincial en esta nueva injerencia, resultaba necesaria la intervención de los privados en materia de hospedaje. Por ello, la ley preveía diferentes estímulos para ese sector con el fin de impulsar la construcción de tres tipos distintos de albergues: los hoteles de ciudad para los residentes comunes cuyo viaje obedeciera a causas y objetivos diversos; los hoteles, hosterías y restaurantes de turismo ubicados en lugares pintorescos cuya clientela sería principalmente de paseantes; y los hoteles termales destinados sobre todo a la atención de pacientes y sus familias. En cada caso, los estímulos se otorgaban de acuerdo al tipo de inversión que hacían los empresarios y suponían desde la simple figuración en guías

\footnotetext{
22 Para el período tenemos datos de la realización de la Feria Industrial en los años 1939, 1940 y 1941. Las industrias incluidas en la promoción fueron: vitivinícola, minera, de la granja, aceitera, conservación y desecación de frutas, cementera, petrolera y destilación de alcohol.

23 A partir de los expedientes presentados solicitando adhesión a las leyes 1216 y 1298 sabemos de la existencia de hoteles privados en los departamentos de San Rafael (2), Luján (1), Tunuyán (1) y Las Heras (1) (Ministerio, 1941, s/p).
}

Anuario de la Escuela de Historia Virtual - Año 11 - No 17 - 2020: pp. 104-127. ISSN: 1853-7049 
oficiales hasta la prima en efectivo, pasando por la exención parcial o total de impuestos provinciales (Recopilación de Leyes, 1938, pp. 367 y ss.). Los emprendimientos que gozaran de cualquiera de los beneficios de la ley $\mathrm{N}^{\circ} 1216$ estarían obligados a tener dentro de sus recintos un lugar destinado a la venta de frutas, flores, vino y otros artículos de producción mendocina. La ubicación, tamaño y estilo quedaban a criterio del inversor, aunque bajo el control estricto del Estado. ${ }^{24}$

Incluso se pensó en impulsar la radicación de familias inmigrantes suizas con conocimientos de hotelería que pudieran asentarse en Mendoza y construir pequeñas hosterías explotándolas dentro de las modalidades de esos servicios en su país de origen y colaborando en el posicionamiento de la provincia como una "verdadera escuela de hotelería" (Cano, 1938, p. 262).

Se promovió, además, la mejora de pequeños hoteles mediante empréstitos de los bancos Nación y de Mendoza, con buenos resultados en alojamientos de la Capital provincial y en los departamentos de Tunuyán, Rivadavia y Luján. La capacidad de alojamiento era tan limitada que desde la DTM se impulsó la habilitación de casas de familia para hospedaje, llegando a relevar alrededor de 126 casas con una capacidad de 622 camas en 1937 (Cano, 1938, p. 259).

Paralelamente, y en un "plan de acción inmediata" para atraer turistas, se habilitó en 1937 sobre terrenos fiscales de la localidad de Potrerillos (Luján de Cuyo) un Camping. Este servicio ofrecido por el Estado constituyó también el primer ensayo que se hacía en el país desde un organismo público. ${ }^{25}$ Con capacidad para 150 personas, el predio contaba con servicio sanitario, pileta de natación, pista de baile y restaurante y cantina anexos, cuyos precios regulaba la DTM. ${ }^{26}$

\footnotetext{
${ }^{24}$ Era facultad de la DTM la elaboración de una Reglamentación Provincial de Turismo sujeta a la aprobación del Ejecutivo que determinara, entre otras cosas, las condiciones en que funcionarían los alojamientos y restaurantes contenidos en esta ley (Recopilación de Leyes, 1938, pp. 367 y ss.).

${ }^{25}$ Fue el Automóvil Club Argentino la primera asociación civil que impulsó desde 1926 los días de campo y a partir de 1930 las excursiones-campamento. En 1937 se instalaron los campings de playa del ACA en Mar de Ajó (Piglia, 2008).

${ }^{26}$ EMETUR, Dirección de Turismo de Mendoza. Folletos y guías informativos, 1937-1942.
} 
Figuras 3. Imágenes del camping organizado en Potrerillos
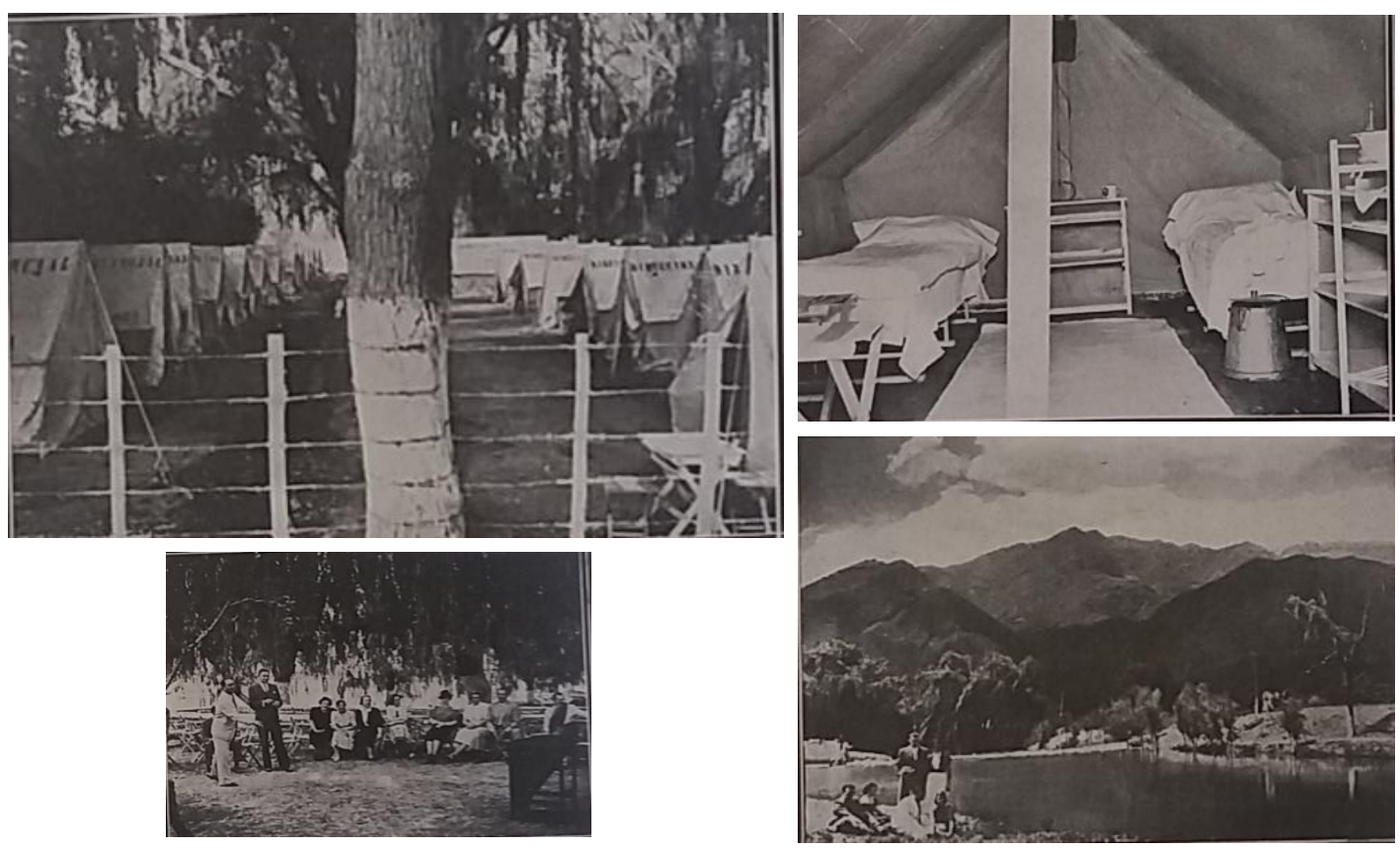

Fuente: La Quincena Social, 1938, pp. 444-445.

Al turista se lo recibía con una carpa armada que contaba con catre, colchoneta, mesa, banco, farol y tacho para agua (Cano, 1938, p. 259). Se habían organizado tours directos desde la Capital Federal por un monto de $\$ 155$, con alojamiento por 15 días y pasajes de ida y vuelta incluidos. Se buscaba que la vida al aire libre y sus beneficios para la salud física y espiritual se incorporaran rápidamente al gusto de la población de grandes centros urbanos del país que pudieran llegar a Mendoza. El Estado impulsaba la creación de espacios turísticos, es decir, espacios organizados por y para el turismo, sobre una estructura socio-espacial dada. ${ }^{27}$

A pesar de los estímulos que proponía la ley $N^{\circ} 1216$, la inversión privada en materia hotelera concretada fue escasa. Entre junio de 1937 y diciembre de 1939 se presentaron veintiún expedientes con la intención de obtener alguno de los beneficios reglamentados, entre ellos, ocho solicitaban fondos para refacciones o ampliaciones y doce lo hacían para iniciar la construcción, de estos últimos solo avanzaron tres pedidos (Ministerio, 1941, s/p). El primer hotel-balneario que se construyó acogiéndose a los beneficios propuestos fue el de la empresa Río Atuel Limitada en El Sosneado, departamento de San Rafael, ${ }^{28}$ también fue de la partida el Hotel Rex en la villa cabecera del mismo departamento (Vicchi, 1942, p. 171).

A esas inversiones se sumó la realizada para el hotel de Villavicencio en 1940. En este caso, el emprendimiento se vio favorecido por la reactivación de la antigua RN 7 y la

\footnotetext{
${ }^{27}$ Sobre la construcción del espacio turístico ver Cazes y Knafou, citados en: Piglia, 2008.

${ }^{28}$ La Libertad, 1 de enero de 1938, s/p.
} 
construcción de los caracoles para tránsito vehicular proyectados para vincular la ciudad de Mendoza con la localidad de Punta de Vacas, enclave donde podía retomarse el viaje en tren hasta el país trasandino. ${ }^{29}$ El hotel se convirtió entre 1940 y 1945 en destino de varias familias de la aristocracia argentina, imposibilitadas de viajar a Europa por efecto de la Segunda Guerra Mundial.

Persiguiendo el posicionamiento de Mendoza como destino turístico destacado, se sancionó en 1938 la ley $N^{\circ}$ 1298. Este nuevo instrumento, que modificaba algunos artículos de la Ley de Turismo, ${ }^{30}$ habilitaba al Estado en la construcción de alojamientos, la administración de su funcionamiento y a realizar contratos concesionarios (Recopilación de Leyes, 1938, pp. 299). Al año siguiente, se reglamentó la ley $\mathrm{N}^{\circ} 1351$ que autorizaba al Ejecutivo a invertir diversas cantidades de dinero para dar cumplimiento a otras leyes para la ejecución de obras públicas, entre ellas se contaban los hoteles y hosterías que proyectaría la DPA (Recopilación de Leyes, 1942b, pp. 251).

\section{La ley $N^{\circ} 1298 / 38$ : arquitectura pública para el ocio y la recreación}

A partir de las nuevas reglamentaciones, se sumó claramente a la acción de la DTM en materia turística la Dirección de Arquitectura de la provincia (DPA). A cargo de los arquitectos Manuel Civit, Arturo Civit ${ }^{31}$ y más tarde de Ewald Weyland, ${ }^{32}$ la DPA participó desde los inicios de la gestión conservadora en obras y proyectos vinculados al ocio y el esparcimiento, pero fue a partir de la ley $\mathrm{N}^{\circ} 1298 / 38$ que incorporó a sus incumbencias una nueva temática de proyecto: la arquitectura hotelera. ${ }^{33}$

Durante la gestión del gobernador Ricardo Videla, se avanzó en el proyecto de construcción del Arco Desaguadero en el límite con la provincia de San Luis. La frase “Bienvenido a Mendoza, la tierra del sol y del buen vino" se propuso como símbolo de

\footnotetext{
${ }^{29}$ La obra de los caracoles de Villavicencio estuvo a cargo de la Dirección Nacional de Vialidad y se desarrolló entre 1935 y 1942. La inversión para el hotel la realizó Ángel Velaz, dueño de la empresa Termas de Villavicencio. El edificio fue diseñado por el estudio Sánchez, Lagos y De la Torre y la construcción dirigida por la dupla local López Frugoni- Ramos Correas (Cremaschi, 2015).

30 Entre las modificatorias estaba la extensión del plazo para que particulares pudieran acceder a los beneficios de la ley 1216/37. Dicho plazo comprendía a los establecimientos que se construyeran desde la sanción de la ley hasta el 31 de diciembre de 1945 y suponían la exención por veinte años del pago de impuestos provinciales (Ministerio de Economía, Obras Públicas y Riego, 1942, pp. 82 y ss.).

${ }^{31}$ Manuel y Arturo Civit se instalaron en Mendoza hacia 1932, luego de haberse graduado como arquitectos en la Universidad de Buenos Aires. Originalmente a cargo de la Oficina de Arquitectura que se convirtió en Dirección en 1936, Manuel dirigió la repartición entre 1932 y 1939, período en que Arturo ejerció el cargo de sub-director; ante la renuncia de Manuel, Arturo asumió el cargo de director entre 1939 y 1941 (Raffa, 2017, pp. 107 y 111).

${ }^{32}$ Egresado también de la Universidad de Buenos Aires, Weyland se afincó en Mendoza hacia 1937 y fue director de Arquitectura entre 1942 y 1945 aproximadamente (Raffa, 2017, p. 241).

${ }^{33}$ Los Civit manejaron en sus discursos los conceptos de higiene, industria constructiva, alojamiento de masas y funcionalidad, sustento teórico que tomaron de base para la resolución de problemas técnicosociales desde la DPA, los cuales ya habían sido esgrimidos por la arquitectura y la planificación de los Estado modernos como Alemania, Francia, Austria o EE.UU., que estos arquitectos tomaban como referencia. En muchos aspectos, la gestión de Weyland es continuadora de los programas impulsados por los Civit y su equipo de trabajo. (Raffa, 2016, 2017, 2018a y 2018b).
}

Anuario de la Escuela de Historia Virtual - Año 11 - Nº 17 - 2020: pp. 104-127. ISSN: 1853-7049 
la recepción cordial de Mendoza para todo forastero que ingresase en su territorio. El conjunto se emplazó sobre la antigua posta del Camino real que unía el Atlántico con el Pacífico. Lo integraban oficinas para la policía caminera, control sanitario, correos, un local para reparaciones de automóviles, una cantina, habitaciones para el pernocte de turistas y viajeros y una bomba de nafta en las inmediaciones. ${ }^{34}$ Para esta obra desde la DPA se hicieron dos propuestas arquitectónicas una en lenguaje racionalista y otra pintoresquista, ${ }^{35}$ que fue la que finalmente por decisión del Ejecutivo se construyó. Se inauguró en octubre de 1936.

Figura 4. Arco Desaguadero

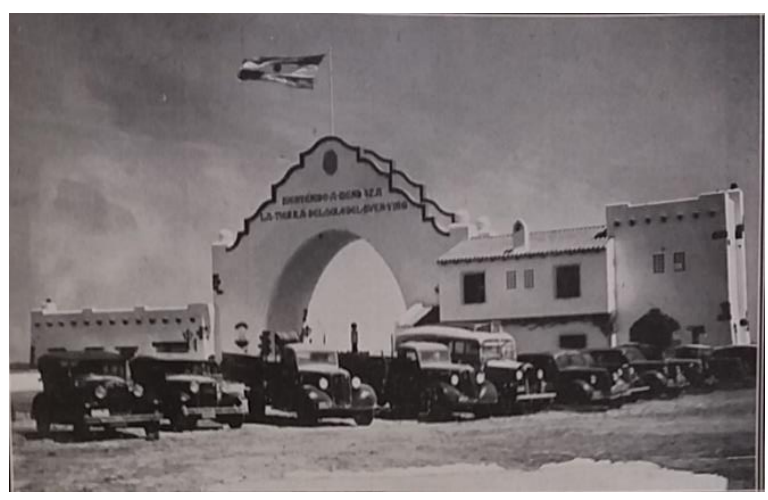

Fuente: La Quincena Social, 1938, pp. 444-445.

El Balneario Playas Serranas fue otro de los proyectos vinculados al ocio y al turismo, que se comenzó a construir en 1935 y se inauguró en 1937. Ventanas continuas, ojos de buey, voladizos, mástiles, pilotes, barandas metálicas, configuraron parte del repertorio utilizado para albergar funciones orientadas al tiempo libre. El edificio fue claramente proyectado a partir de un lenguaje racionalista de reminiscencias corbusieranas, con formas puras y volúmenes suspendidos en los extremos, se asentó en el extremo sureste del lago del Parque General San Martín. Derivado del principio racionalista del "arte para todos", el proyecto redujo la arquitectura a un servicio social-funcional (Raffa, 2009).

El balneario fue pensado como un elemento de solaz e higiene para la población y los turistas, que aportaría la posibilidad de la práctica de la natación y las reuniones sociales

\footnotetext{
${ }^{34}$ La Libertad, 13 de octubre de 1936, p. 4.

${ }^{35}$ El racionalismo se originó en Europa después de la Primera Guerra Mundial. Sus objetivo fue encontrar un camino intermedio entre la renuncia a la imitación de lo antiguo y a un excesivo tecnicismo estandarizado. A partir de 1925 el lenguaje racionalista y sus vertientes se difundieron por Europa y luego por América.

Inicialmente de carácter nacional y vanguardista, principalmente en Inglaterra, Francia y Alemania desde mediados del siglo XIX, el pintoresquismo tuvo una gran difusión en nuestro medio y una notable aceptación como lenguaje de la Arquitectura para el "ocio".
} 
de "todas las clases sociales". Con fácil acceso por diversas calles, la orientación de la construcción se determinó de modo que los bañistas aprovecharan la irradiación solar. Tres mil personas podían hacer uso cómodamente de las instalaciones que contenían vestuarios, salas de reunión o baile, dos terrazas altas, restaurante e instalaciones de radio, además de una playa y un trampolín hacia el lago. Periódicamente se hacían revisaciones médicas a los bañistas y la entrada era a un precio "popular". ${ }^{36}$ El lugar comenzó a concesionarse a partir de octubre de 1937.

A fines de ese mismo año se proyectó la remodelación del chalet existente en el Cerro de la Gloria, pero esta vez adhiriendo al lenguaje pintoresquista. Las obras sobre este edificio, que convertido en hostería pasó a formar parte poco tiempo después del Zoológico diseñado por Ramos Correas, se extendieron hasta 1941 (Raffa, 2011).

Figuras 5. Balneario Playas Serranas y hostería en Cerro de la Gloria
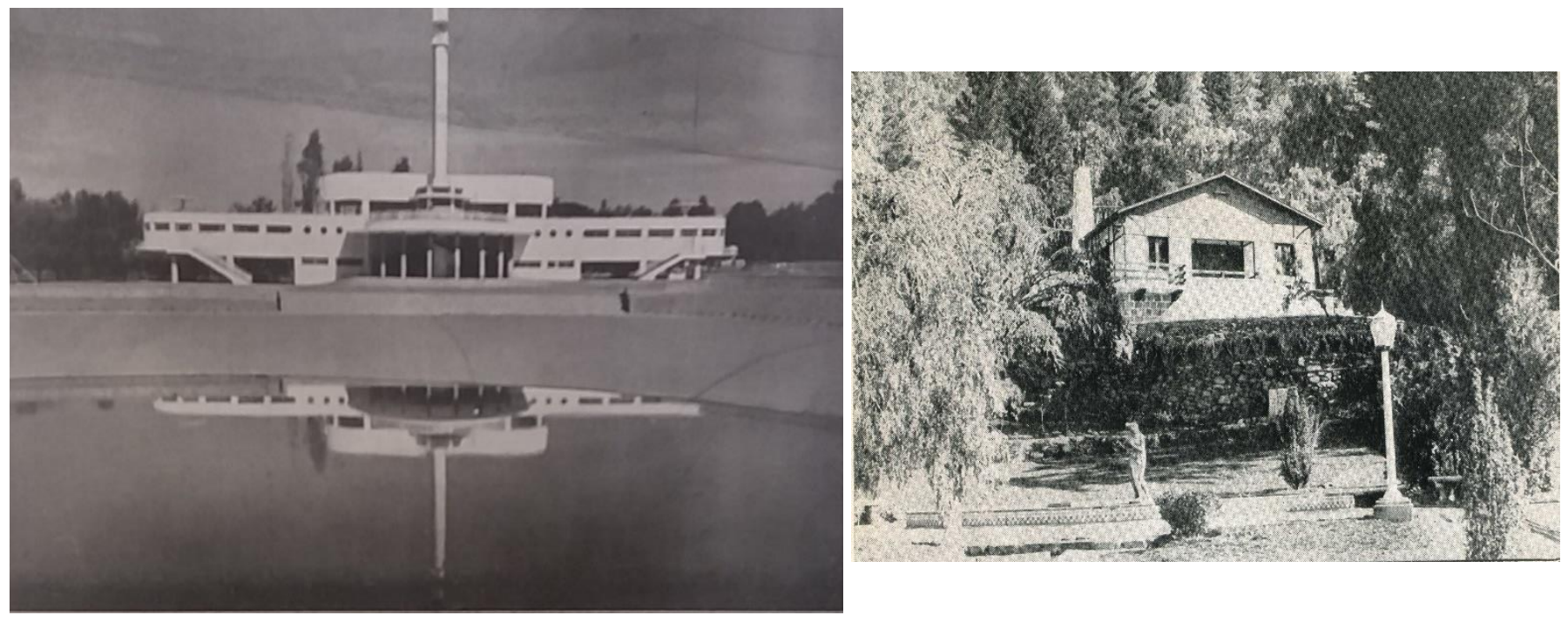

Fuentes: Ministerio, 1941.

Para el servicio de alojamiento y comida, la DPA proyectó distintos hoteles y hosterías. ${ }^{37}$ Se realizaron incluso prototipos para quioscos de informaciones y almacenes de campaña con alojamientos para turistas que no llegaron a construirse, pero que denotan una actividad proyectual intensa, vinculada a la temática del turismo. Muchos de esos prototipos fueron elaborados por el arquitecto Mario Brishigelli, quien después de un corto período como soporte técnico en la DTM, se incorporó en 1937 a la DPA (Cremaschi en Raffa, 2017, p. 81).

En todos los casos, el lenguaje arquitectónico adoptado fue el pintoresquista en sus variantes californiano o normando, un estilo que tuvo una gran aceptación en los

\footnotetext{
${ }^{36}$ La Libertad, 9 de enero de 1938, s/p.

${ }^{37}$ En la publicación que resume la gestión del gobernador Guillermo Cano, aparece el croquis de un hotel monumental de líneas racionalistas, que se presume fue proyectado para la capital provincial por la DPA, pero que finalmente no fue construido (Cano, 1938).
} 
proyectos de arquitectura para el ocio en nuestro país y suponía, en términos simbólicos, un arraigo a lo regional. Las propuestas resultantes se caracterizaron por composiciones aditivas, expresivas y contrastantes en cubiertas y volúmenes, con fachadas asimétricas y plantas de gran riqueza espacial y plástica. El aspecto rústico se adaptaba a la provincia, según los proyectistas, por las características del clima, la topografía del suelo y la luminosidad de la región. A su vez, el uso de materiales de producción u origen regional -tejas, madera, piedra y ladrillos- contribuía a abaratar los costos de la obra.

En zonas suburbanas y de montaña, se levantaron la Hostería de Los Molles, en el departamento de Malargüe y la Hostería del Río Mendoza y el Hotel de Potrerillos, en Luján de Cuyo. En 1942, se inició la construcción del nuevo Hotel de Uspallata, en el departamento de Las Heras. Otra alternativa de albergue turístico fueron los proyectos de vivienda para el "peón caminero", que, emplazadas a la vera de los caminos, podían funcionar en caso de necesidad como hospedaje. De esa tipología se construyó un ejemplo en la localidad de Calmuco, en el sur provincial, hacia 1940 (Raffa, 2015).

La hostería de Los Molles comenzó a construirse durante la gestión de Guillermo Cano y se inauguró durante la gobernación de su sucesor. Por la falta de equipamiento en la zona, el edificio nucleó también una sala de primeros auxilios, oficina policial y aulas. El emplazamiento fue elegido entre otras variables por las propiedades termales de las aguas de la zona.

En las inmediaciones del dique Cipolletti, en el departamento de Luján de Cuyo, se construyó otra hostería entre febrero y agosto de 1940 en la que se invirtieron alrededor de \$72.000. El proyecto incluyó en planta baja un living-room, comedor, cocina, sanitarios, office y dependencias de servicio, amplias galerías, terraza y pérgolas. En la planta alta se distribuyeron cuatro dormitorios, tres baños, terrazas y balcones para poder admirar el entorno. En las inmediaciones del edificio se generó un lago artificial con una isla en el medio. ${ }^{38}$ Esta hostería estuvo asociada a un camping, que durante años fue concesionado al Automóvil Club Argentino.

El Hotel de Potrerillos, por su parte, se levantó entre febrero de 1940 y noviembre de 1941, con una inversión final superior a los \$ 800.000. Para su emplazamiento, se tuvo en cuenta la magnificencia del paisaje y el sentimiento de respeto y amor por las tradiciones históricas, pues, fue en ese valle donde en 1817, a poco de iniciada la marcha del Ejército Libertador, se produjo la batalla de Potrerillos. Un acto simbólico que, desde el poder político, instaba, al menos discursivamente, a seguir el ejemplo de los valientes granaderos que defendieron a la Patria. ${ }^{39}$

El edificio contaba con cuarenta y tres habitaciones y veinte baños; se incorporaron en él galerías, balcones y terrazas, que hacían más fluida la conexión con el paisaje. Poseía, además, los últimos adelantos técnicos en lo referido al confort, que incluían la provisión de agua caliente y calefacción central. Los jardines, proyectados por el

\footnotetext{
${ }^{38}$ Los Andes, 1 de enero de 1941, p. 2

${ }^{39}$ Los Andes, 17 de febrero de 1941, p. 7.
}

Anuario de la Escuela de Historia Virtual - Año 11 - Nº 17 - 2020: pp. 104-127. ISSN: 1853-7049 
ingeniero Benito J. Carrasco, seguían el diseño de un parque español con fuente, pérgolas y bancos..$^{40}$

Figuras 6. Hostería del Río Mendoza, Hostería de Los Molles, Hotel de Potrerillos y proyecto para la casa del peón caminero

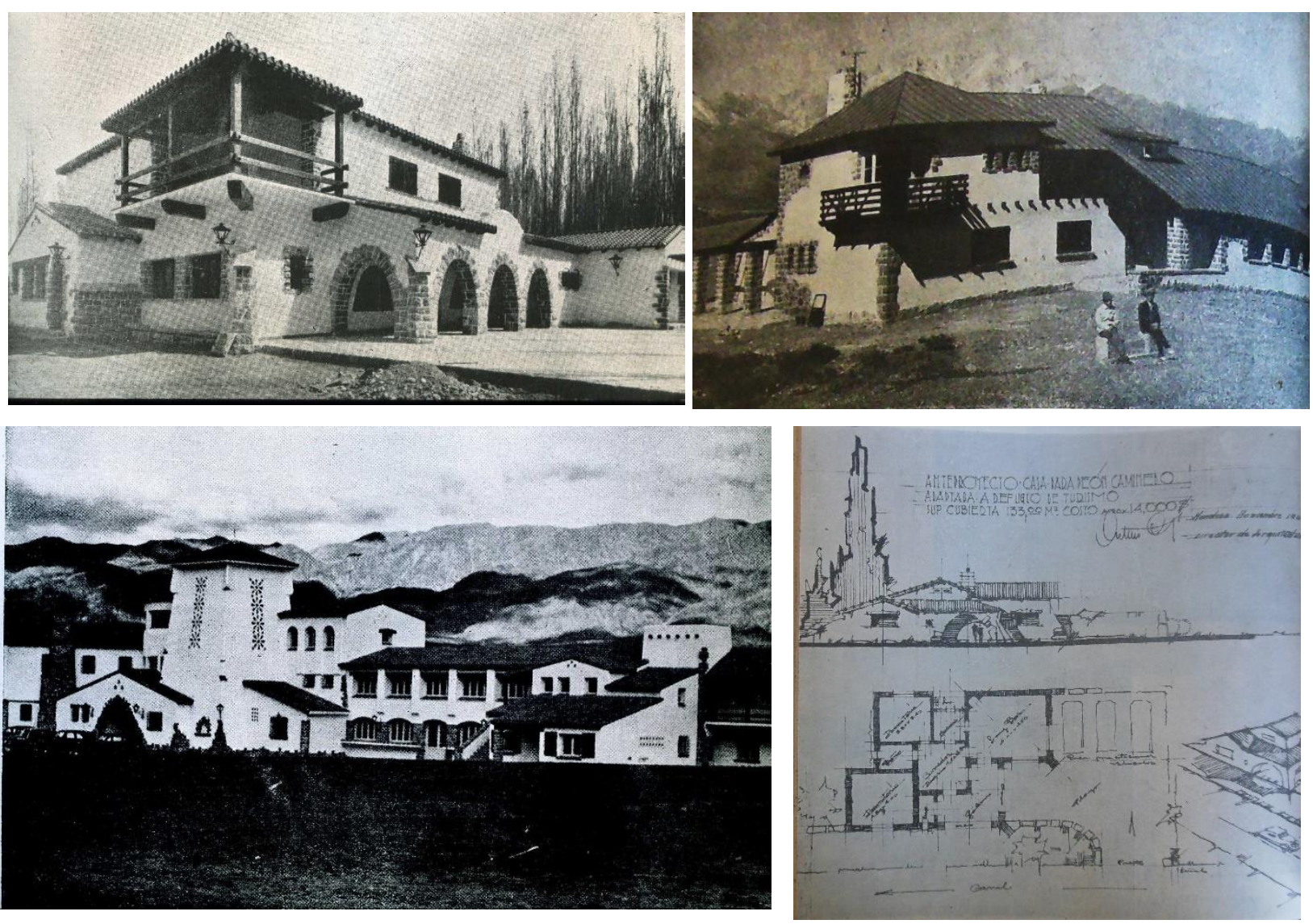

Fuente: Ministerio, 1941.

Durante la gestión del gobernador Vicchi, y con Romero Day ${ }^{41}$ nuevamente como ministro, se volvió a insistir sobre la necesidad de destinar recursos a la inversión en hotelería, ofreciendo primas en efectivo a privados o invirtiendo en hoteles de propiedad fiscal que luego se concesionarían, pero todos regulados por la DTM y cuyos planos serían aprobados por la DPA (Decreto 881 E/41 en Vicchi, 1941).

\footnotetext{
${ }^{40}$ Benito Carrasco (Buenos Aires, 1877-1958), ingeniero agrónomo y paisajista argentino, se desempeñó como Director de Parques y Paseos de la ciudad de Buenos Aires. En 1915 fue contratado para realizar un proyecto de remodelación de la trama urbana de la ciudad de Mendoza que finalmente no se concretó (Raffa, 2004). En 1937, volvió a Mendoza para aconsejar al Ejecutivo sobre la mejor forma de construir hoteles de turismo en Potrerillos (Los Andes, 9 de junio de 1937, p. 6).

${ }^{41}$ Frank Romero Day (1897-1950), estudió Ingeniería Agrícola en Francia, en Mendoza se dedicó a la explotación de las propiedades de la familia. Fue Diputado Nacional (1924) y ministro de Industrias, Obras Públicas y Riego durante la gestión de Guillermo Cano (1935-1938) y Adolfo Vicchi (1941-1943), desde su Ministerio se impulsó la Ley de Turismo y la creación de la Fiesta de la Vendimia (Romero Day, 2013, pp. 15-30).
} 
A través de la ley $\mathrm{N}^{\circ}$ 1401/41, complementaria de las reglamentadas en 1937, 1938 y 1939, el Ejecutivo quedó facultado para invertir hasta \$2.000.000 en los denominados “Títulos de Edificación de Hoteles". Como garantía de pago a los portadores de títulos, se dispusieron las sumas que se recaudarían de las concesiones de los hoteles y hosterías construidas por el Estado y de las producidas por su explotación, cuando esta dependiese del Estado (Vicchi, 1941, pp. 169 y ss.). Con esta nueva ley, se buscaba la ampliación de la oferta de hoteles "para todo el año", donde se ofreciera confort moderno, pero lejos de las tarifas de los hoteles de lujo para que pudieran acceder a él los sectores medios.

Junto a aquella norma, los decretos 537 y 565 E de junio de 1941 proponían un plan orgánico de instalación de hoteles y hosterías estableciendo cinco zonas en la provincia y determinando la cantidad de plazas de alojamiento para cada una de ellas y el llamado a licitación, respectivamente. ${ }^{42}$

En el marco de estas medidas, el decreto 755 de julio de 1942 aprobó los planos, especificaciones técnicas y presupuesto ejecutados por la DPA a cargo de Ewald Weyland para la construcción del Gran Hotel de Turismo en el Valle de Uspallata por un valor inicial de $\$ 797.997,53$. El hotel contaba con frigorífico, lavandería, peluquería, bar, conserjería, tintorería y un ala para el alojamiento del personal, entre otras comodidades. Se emplazó sobre un terreno que la provincia le compró al Banco Hipotecario Nacional. ${ }^{43}$

Se previó, además, un plan de urbanización para el Valle con el objetivo de que los alrededores del hotel que estaba por construirse tuvieran la categoría espacial de una región de alto turismo (Vicchi, 1941, p. 579). La propuesta urbanística, encargada al Ingeniero Benito Carrasco, debía ser presentada al Ejecutivo en un plazo máximo de tres meses y suponía: el proyecto de plantaciones en general, la formación de un gran parque, el mejoramiento del paisaje natural, el proyecto de canchas y campos de deportes apropiados al clima y la topografía, el estudio de los caminos de acceso desde la ruta a Chile y una villa de residencias veraniegas. Considerado como uno de los lugares de mayor atractivo de la provincia y paso obligado en el camino a Chile, Uspallata se unía así al listado de enclaves de montaña sobre los que el Estado provincial hacía su inversión.

\footnotetext{
42 Primera zona: Capital, Godoy Cruz, Guaymallén y Las Heras (hasta 500 habitaciones); segunda zona: alrededores de la Ciudad de Mendoza dentro de un radio de $35 \mathrm{~km}$ desde el Km 0 (hasta 200 habitaciones); tercera zona: San Martín, Junín, Rivadavia, Santa Rosa y La Paz (hasta 100 habitaciones); cuarta zona: San Carlos, Tunuyán, San Rafael y General Alvear (hasta 100 habitaciones); quinta zona: Tupungato y zona cordillerana (hasta 300 habitaciones) (Vicchi, 1941, pp. 274 y ss.). Weyland avanzó a nivel de proyecto en la ideación de una hostería en el Manzano Histórico, sitio vinculado a la gesta sanmartiniana, en el departamento de Tunuyán, que finalmente no se construyó.

${ }^{43}$ El hotel no llegó a ser inaugurado por la gestión conservadora a raíz del golpe de Estado de 1943. El edificio fue transferido mediante la ley 1671/47, al Instituto Argentino de Promoción del Intercambio (IAPI) al costo neto. Este organismo fue el que lo cedió a la Confederación General de Empleados de Comercio en 1948, que lo rebautizó como Presidente Perón (Raffa, 2018c).
} 
Figura 7. Hotel de Uspallata

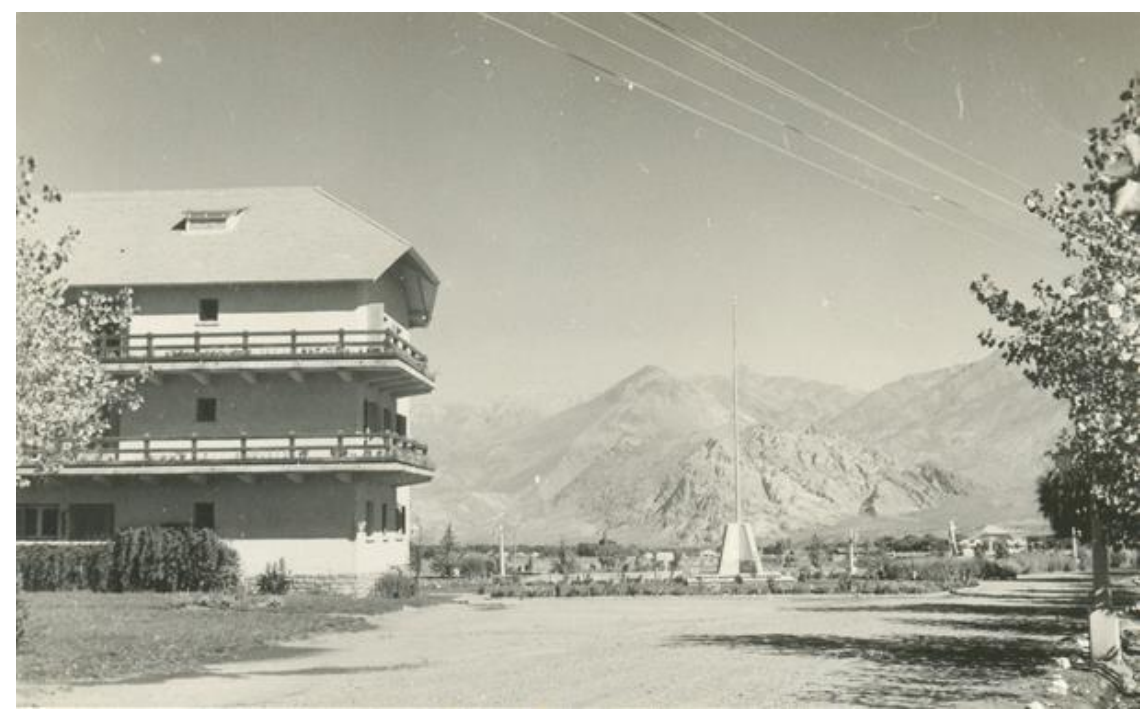

Fuente: Archivo de la autora.

Seguidamente, el decreto 826/42 aprobó la licitación para la construcción de una hostería que completara el conjunto de Desaguadero, siguiendo los lineamientos previstos por la DPA (Vicchi, 1943).

En el trabajo de fomentar el turismo de montaña, también durante la gestión de Vicchi, se destinaron fondos para la adquisición de vehículos que transportaran deportistas desde el Hotel de Potrerillos hasta una hostería -refugio emplazado en el Cordón del Plata-, lugar donde se estaban haciendo trabajos para habilitar pistas de sky, patinaje sobre hielo, deslizamiento en trineo, etc., impulsando la práctica de deportes de invierno (Vicchi, 1942, p. 575).

El golpe militar de junio de 1943 dejó en suspenso varias de las iniciativas en pos de la promoción turística de Mendoza, particularmente las impulsadas durante la gestión de Adolfo Vicchi. Esas políticas fueron retomadas y re-significadas a partir de 1946 en el marco de las campañas de turismo social impulsadas durante el primer peronismo. Con una limitada inversión en hotelería para los viajes organizados por los gobiernos provincial, nacional y por los gremios a Mendoza, durante la primera presidencia de Perón, se utilizó el equipamiento existente en la provincia en su mayoría, construido entre 1932 y 1943 (Raffa, 2018c). 
Figura 8. Ubicación del equipamiento para el turismo en la provincia construido entre 1932-1943

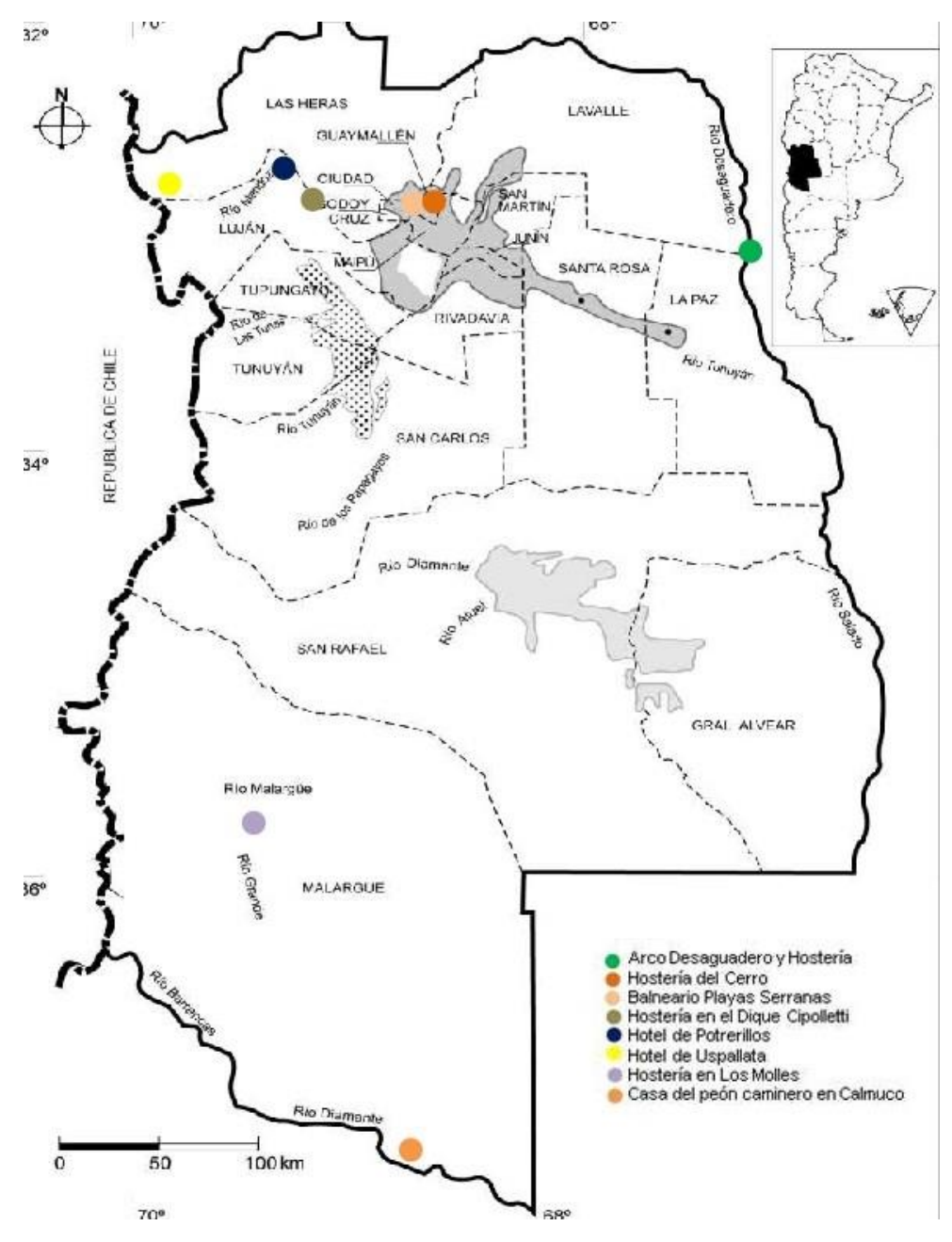

Fuente: Elaboración propia

\section{Conclusiones}

Mendoza desarrolló sus propias políticas vinculadas al turismo sentando un precedente sobre el resto de las gestiones provinciales. Con cuatro leyes en cinco años, el ciclo conservador equipó a la provincia con hoteles y hosterías, balnearios, caminos, monumentos, campings, parques; desarrolló guías de viaje, mapas e impulsó la realización de fiestas y exposiciones y la promoción de las industrias locales.

En términos económicos, el desarrollo de esta industria se hizo posible por la financiación de las distintas leyes que la regulaban a través de la emisión de títulos de deuda interna, una práctica que resultó habitual en la gestión de las políticas estatales del período, sobre todo, para financiar la construcción de obra pública y que permitió el 
"avance" de la provincia en términos materiales sin depender de las partidas nacionales (Raffa, 2018a; 2018b).

La oportunidad de turistificar en sentido positivo a Mendoza, es decir, de convertirla en un lugar que empezara a recibir una fluencia cada vez más alta de turistas, se basó en la visión política generalizada entre los dirigentes provinciales (y nacionales), de considerar al turismo como instrumento de progreso. Un adelanto que buscaba impulsar a las industrias y al comercio, que invitaba a la inversión de capitales, que pretendía mejorar y difundir el consumo de productos locales y el conocimiento de la propia tierra.

En 1937 llegaron a la provincia 26.142 turistas, en 1938 fueron 33.848, en 1939 pasaron a 39.014 y en el año 1940 a 43.464 (Corominas, 1942). Estas cifras, accesibles a partir de la creación de la DTM, suponen un crecimiento de alrededor de un $90 \%$ en la afluencia de turistas a la provincia en un lapso de cuatro años. Un resultado que, aunque parcial, indica una tendencia positiva en la implementación del turismo como estrategia económica y cultural durante la gestión liberal-conservadora en Mendoza. Simultáneamente, marca el paso entre las experiencias del turismo/ocio de élite de principios del siglo $\mathrm{XX}$, y la democratización social de esta práctica durante el primer peronismo.

\section{Referencias bibliográficas y fuentes:}

Ballent, A. (2005). Kilómetro Cero: la construcción del universo simbólico del camino en la Argentina de los años treinta. Boletín del Instituto de Historia Argentina y Americana Dr. Emilio Ravignani, vol. 2, 107-137.

Ballent, A. y Gorelik, A. (2002). País urbano o país rural: la modernización territorial y su crisis. En A. Cataruzza (Dir.), Crisis económica, avance del Estado e incertidumbre política (1930-1943). Col. Nueva Historia Argentina, tomo VII (pp. 143-198). Buenos Aires: Sudamericana.

Bruno, P. (2010). Los hoteles de turismo (1930-1955): piezas claves del territorio turístico de la Argentina. Registros, vol. 9, 54-80.

Cano, G. (1938). 3 Años de Gobierno. Mendoza: Imprenta Oficial.

Corbin, A. (1993). El territorio del vacío. Occidente y la invención de la playa (1750-1840). Barcelona: Mondadori (Grijalbo).

Cremaschi, V. (2015). Hoteles monumentales. El impulso al turismo durante los gobiernos demócratas en la provincia de Mendoza, Argentina (1930-1943). Caiana, vol. 6, 101-118.

Corominas Segura, R. (1942). Labor de Gobierno 1938-1941, tomo 1. Mendoza: Ed. Oficial. Lacoste, P., et al. (1996). Grandes obras de Mendoza. Mendoza: Uno.

Marchionni, F. (2012). Arquitectura efímera, rituales y fiesta. Andinas, vol. 1, 64-77.

Ministerio de Economía, Obras Públicas y Riego (1941). Memoria correspondiente al período 1938-1941, tomo IV. Mendoza: Ed. Oficial. 
Ospital, M. S. (2005). Turismo y territorio nacional en Argentina. Actores sociales y políticas públicas, 1920-1940. EIAL, vol. 16 (2), 63-84.

Pastor, G. y Raffa, C. (2013). Huellas de relatos en movimiento. Los patrimonios emergentes del itinerario argentino-chileno de casas de postas: la ruta mendocina. En M. A. Nicoletti y P. Núñez (Comps.), Araucanía-Norpatagonia: la territorialidad en debate. Perspectivas ambientales, culturales, sociales, políticas y económicas (pp. 32-53). Bariloche: IIDYPCA- CONICET/ UNRN.

Pastoriza, E, (ed.) (2003). Las puertas al mar. Buenos Aires: Biblos.

Pastoriza, E. (2011). La Conquista de las vacaciones. Buenos Aires: Edhasa.

Pastoriza, E. (2008). Estado, gremios y hoteles. Mar del Plata y el peronismo. Estudios Sociales, vol. 34 (1), 121-147.

Pastoriza, E. y Piglia, M. (2012). Asociaciones civiles, empresas y Estado en los orígenes del turismo nacional. Anuario del IEHS, vol. 27, 393-416.

Piglia, M. (2008a). Ciudades de lona: el ACA y la construcción de los campings como lugares turísticos en la entreguerra (1926-1940). En P. Zusman, C. Lois y H. Castro (Coords.), Viajes y geografías. Turismo, migraciones y exploraciones en la construcción de lugares (pp. 131-148). Buenos Aires: Prometeo.

Piglia, M. (2008b). La incidencia del Touring Club Argentino y del Automóvil Club Argentino en la construcción del turismo como cuestión pública (1918-1929). Estudios y Perspectivas en Turismo, vol. 1 y 2 (17), 51-70.

Piglia, M. (2011a). The Awakening of Tourism: The Origins of Tourism Policy in Argentina, 1930-1943. Journal of Tourism History, vol. 3, 57-74.

Piglia, M. (2011b). Automóviles, nafta y caminos: los vínculos entre el Automóvil Club Argentino y el Estado en los años treinta. Entrepasados, vol. 36-37, 155-174.

Piglia, M. (2012). En torno a los parques nacionales: primeras experiencias de una política turística nacional centralizada en la Argentina 1934-1950. Pasos, vol. 10, 61-73.

Piglia, M. y Pastoriza, E. (2013). El turismo y sus historias. Introducción al Dossier: El turismo como campo de reflexión (indagación) histórica: políticas públicas, prácticas y representaciones. Registros, vol. 9, 2-7.

Piglia, M. y Pastoriza, E. (2017). La construcción de políticas turísticas orientadas a los sectores medios durante el primer peronismo: Argentina 1946-1955. Licere, vol. 20 (1), 411- 452.

Pérez Ghilou, D. (1997). Ensayos sobre la historia política institucional de Mendoza. Buenos Aires: Senado de la Nación.

Raffa, C. (2004). El urbanismo de Benito Carrasco: entre Parques y Jardines y la propuesta para la ciudad de Mendoza. Registros, vol. 2, 149-166.

Raffa, C. (2009). La vanguardia racionalista en Mendoza: la obra de los arquitectos Manuel y Arturo Civit. Revista de Historia de América, vol. 139, 181-205.

Raffa, C. (2011). La obra paisajística de Daniel Ramos Correas en Mendoza. En R. Gutiérrez (Ed.), Manifestaciones francesas en Argentina. Del Academicismo a la Modernidad (1889-1960) (pp. 105-110). Buenos Aires: CEDODAL. 
Raffa, C. (2015). Individuales y colectivas. La vivienda popular en la agenda técnica y política del período conservador (Mendoza, 1932-1943). Dossier: La vivienda en distintas latitudes. Argentina. 1900-1955. Revista de Historia Americana y Argentina, vol. 50 (2), 37-63.

Raffa, C. (2016). Propuestas técnicas y prácticas políticas: arquitectos en la Dirección de Arquitectura (Mendoza, 1932-1955). En F. Rodríguez Vázquez y C. Raffa (Coords.), Profesionalizando un Estado provincial, Mendoza (1890-1955) (pp. 84-111). Mendoza: IHAYA- UNCuyo.

Raffa, C. (Dir.) (2017). Arquitectos en Mendoza. Biografías, trayectorias profesionales y obras, tomo 1. Mendoza: FFyL- UNCuyo.

Raffa, C. (2018a). Arquitectura pública y asistencia social en Mendoza: obras para el amparo de menores (Argentina, 1932-1943). Coordenadas, vol. 5 (1), 22-38.

Raffa, C. (2018b). El avance del Estado: arquitectura y políticas públicas en el territorio (Mendoza-Argentina, 1932-1943). Avances del Cesor, vol. 19, 25-47.

Raffa, C. (2018c). Turismo social: entre simbolismos y materializaciones. En C. Raffa e I. Hirschegger (Dirs.), Proyectos y concreciones. Obras y políticas públicas durante el primer peronismo en Mendoza (1946-1955) (pp. 173-197). Mendoza: IHAyA- SCTyP (UNCUYO).

Recopilación de Leyes (1938). Tomo VII, serie 2. Mendoza: Ed. oficial.

Recopilación de Leyes (1942). Tomo I, serie 3. Mendoza: Ed. oficial.

Recopilación de Leyes (1942b). Tomo II, serie 3. Mendoza: Ed. oficial.

Romero Day, R. (2012). Frank Romero Day. Familia, actuación e impronta en Mendoza. Revista de la Junta de Estudios Históricos de Mendoza, vol. 10-11, tercera época, 15-30.

Torre, J. C. y Pastoriza, E. (2002). La democratización del bienestar. En J. C. Torre (Dir.), Los años peronistas, Col. Nueva Historia Argentina, tomo VIII, (pp. 257-312). Buenos Aires: Sudamericana.

Vicchi, A. (1941). Labor Gubernativa (marzo, abril, mayo y junio), tomo 1. Mendoza: Ed. Oficial.

Vicchi, A. (1943). Labor Gubernativa (julio-diciembre 1942 y enero 1943), tomo 5. Mendoza: Ed. Oficial.

Vázquez-Presedo, V. (1976). Estadísticas Históricas Argentinas, segunda parte (1914-1939). Buenos Aires: Macchi.

Walton, J. (1983). The English Seaside Resort. A Social History, 1750-1914. New York: Leicester University Press-St. Martin's Press.

Para citar este artículo:

Raffa, Cecilia (2020). El turismo como estrategia del Estado: visiones políticas y aportes técnicos en Mendoza (1936-1943). Anuario de la Escuela de Historia Virtual, 17, 104-127. 